\title{
Wavelength Calibrations in the Far Infrared (30 to 1000 Microns)
}

\author{
K. Narahari Rao, ${ }^{\star}$ R. V. de Vore, ${ }^{\star}$ and Earle K. Plyler
}

(April 3, 1963)

\begin{abstract}
A discussion is presented of certain calibration procedures employed in the region 30 to 1000 microns. Calculated positions for the pure rotational absorption lines of the CO, $\mathrm{HCN}$, and $\mathrm{N}_{2} \mathrm{O}$ molecules are given, and a map of the pure rotational absorption lines of the $\mathrm{H}_{2} \mathrm{O}$ molecule as recorded with a Perkin-Elmer model 301 spectrophotometer is shown.
\end{abstract}

\section{Introduction}

During the recent meetings of the Triple Commission for Spectroscopy, there have been discussions about the need for systematizing the wavelength standards and the wavelength calibration techniques for the infrared region. To partially meet this need, a report $[1]^{1}$ has been compiled consisting of maps and the spectral positions of several vibration rotation bands occurring in the region 2.5 to $15 \mu$. Evidently, it is important to provide such data for use in the far infrared at wavelengths longer than $15 \mu$ and extending into the millimeter region of the electromagnetic spectrum. Furthermore, it is of interest to examine critically all the currently available wavelength calibration techniques because of the impossibility of devising one procedure that can be adopted for the entire spectral region between 30 to $1000 \mu$.

\section{Experimental Procedure}

In the far infrared region we observe mostly the pure rotational spectra of molecules. It is possible to calculate the positions of the pure rotational lines of a diatomic molecule like $\mathrm{CO}$ and linear triatomic molecules like $\mathrm{HCN}$ and $\mathrm{N}_{2} \mathrm{O}$ by employing the rotational constants derived from studies of the microwave and near infrared absorption spectra of these molecules. One may conceive of three different ways in which the pure rotational lines of simple molecules such as $\mathrm{CO}, \mathrm{N}_{2} \mathrm{O}$, and $\mathrm{HCN}$ can be used for the calibration of far infrared grating spectrometers: (i) In the case of spectrometers facilitated to determine the angular rotation of the grating, it is

*The Ohio State University, Columbus, Ohio.

${ }^{1}$ Figures in brackets indicate the literature references at the end of this paper. possible to employ the grating equation

$$
\nu=n K \operatorname{cosec} \theta,
$$

$n$ being the spectral order, $K$ the grating constant (expressed in $\mathrm{cm}^{-1}$ ), and $\theta$ the angle between the central image and the spectral line located at $\nu \mathrm{cm}^{-1}$. Observations on the pure rotational lines of $\mathrm{CO}, \mathrm{HCN}$, and $\mathrm{N}_{2} \mathrm{O}$ can lead to a value for the grating constant $K$. This value for $K$ can then be used in the subsequent measurements of the far infrared lines. Evidently, we should assume that the value for $K$ does not change between the time the standards (viz, $\mathrm{CO}, \mathrm{HCN}$, and $\mathrm{N}_{2} \mathrm{O}$ ) are recorded and the time when the angular positions of the far infrared lines are measured. If several repetitive records are obtained, it is possible to minimize the errors arising from changes in the grating constant. The accuracy of the measurements made with this method depends on the accuracy with which the angular rotations of the grating can be determined. (ii) In commercial instruments, like the PerkinElmer model 301 far infrared spectrophotometer, the recorded data are considered to be linear in wave number units. This is accomplished by using [2]a "cosecant drive" for rotating the grating. "Pip" marks are recorded periodically on the chart. It has been our experience that, for a particular installation of the grating, the locations of these marks with respect to far infrared spectra are reproducible to accuracies of about $\pm 0.03 \mathrm{~cm}^{-1}$ at $100 \mu$. With these limitations in mind, it should be possible to calibrate these "pip" marks by making observations on the pure rotational lines of the above simple molecules. (iii) A technique which has been extensively employed in the near infrared spectral regions consists in the simultaneous observation, by use of double-pen recorders, of two beams of radiation passing through the spectrometer at the 
same time $[3,4]$. One of two beams consists of the infrared spectra to be measured and the other provides a wave number scale to enable the determination of relative positions of the infrared spectral lines. If it becomes possible to impress a wave number scale on the far infrared spectra, the absolute positions of the scale can be determined by making use of the pure rotational lines of $\mathrm{CO}, \mathrm{N}_{2} \mathrm{O}$, and HCN molecules. This technique of employing two beams of radiation may prove especially useful when investigations are made with grating spectrometers operating in a vacuum. The calibrating radiation may consist of higher orders of atomic lines or higher orders of vibration rotation bands of simple molecules. Some of the atomic lines of mercury, helium and neon have sufficient intensity so that they can be detected in orders above one hundred. Figure 1 shows a part of the higher orders of the $2 \mu$ line of helium $\nu_{\mathrm{a} \text { ir }}=4858.874 \mathrm{~cm}^{-1}$ and $\nu_{\mathrm{vac}}=4857.525 \mathrm{~cm}^{-1}$ from the 85th to 110th orders as observed with a 90 lines per inch grating and a lead sulfide cell as detector. The slits of the spectrometer should be sufficiently narrow to resolve the spectra of the various orders shown in figure 1 . We are emphasizing this point because the physical slits used in a far infrared spectrometer are usually quite wide (of the order of a few $\mathrm{mm}$ ) and therefore it may become necessary to use an independent set of slits for producing wave number markers like those shown in figure 1 .
This method of calibration can be checked on an instrument by using the higher orders of a definite atomic line for calibration and then measuring the positions of the higher orders of other known atomic lines.

The feasibility of employing integral relation between wavelengths of overlapping orders for obtaining spectral positions in the near infrared when modern gratings are used has been discussed adequately in previous publications $[5,6]$. Since the procedures employed for ruling far infrared gratings may differ from the precise techniques used for ruling near infrared gratings, it is important to ascertain the validity of the applicability of integral relation between overlapping orders when gratings ruled for use in far infrared are employed.

For the region from 200 to $400 \mathrm{~cm}^{-1}$ the pure rotational absorption spectrum of diatomic and simple polyatomic molecules are usually of low intensity. However, the pure rotational lines of water vapor are of sufficient intensity for this region. The higher orders of molecular bands can be obtained in this region and are useful. For instance, the $\nu_{2}$ absorption band of $\mathrm{HCN}$ is well suited for this purpose since it has been precisely measured [7] and the band contains many rotational lines separated by about $3 \mathrm{~cm}^{-1}$. Since a well resolved spectrum of this band has not been published, a trace of the observed band is included in figure 2 .

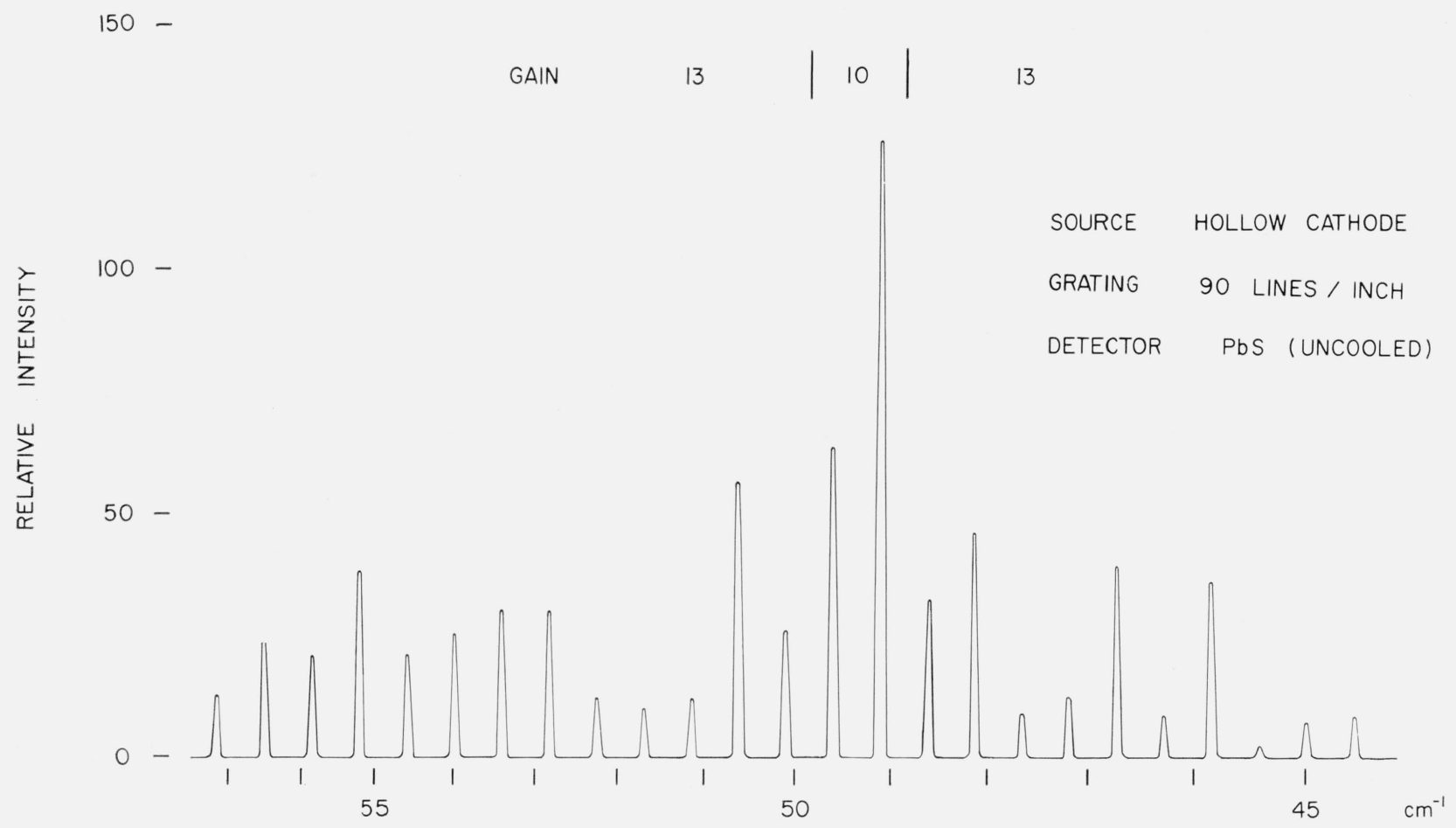

FIGURE 1. $2 \mu$ He line recorded in higher orders (gain refers to the model 107 Perkin-Elmer amplifier). 
SOURCE NERNST GLOWER

PATH LENGTH $20 \mathrm{~cm}$

$100 \%$

PRESSURE

$7 \mathrm{~cm} \mathrm{Hg}$

$5.5 \mathrm{~cm} \mathrm{Hg}$

$4.5 \mathrm{~cm} \mathrm{Hg}$

$2.5 \mathrm{~cm} \mathrm{Hg}$

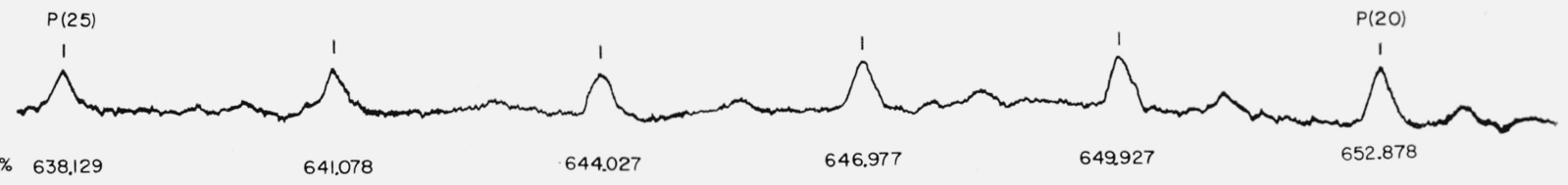

$100 \%$

$0.8 \mathrm{~cm} \mathrm{Hg}$
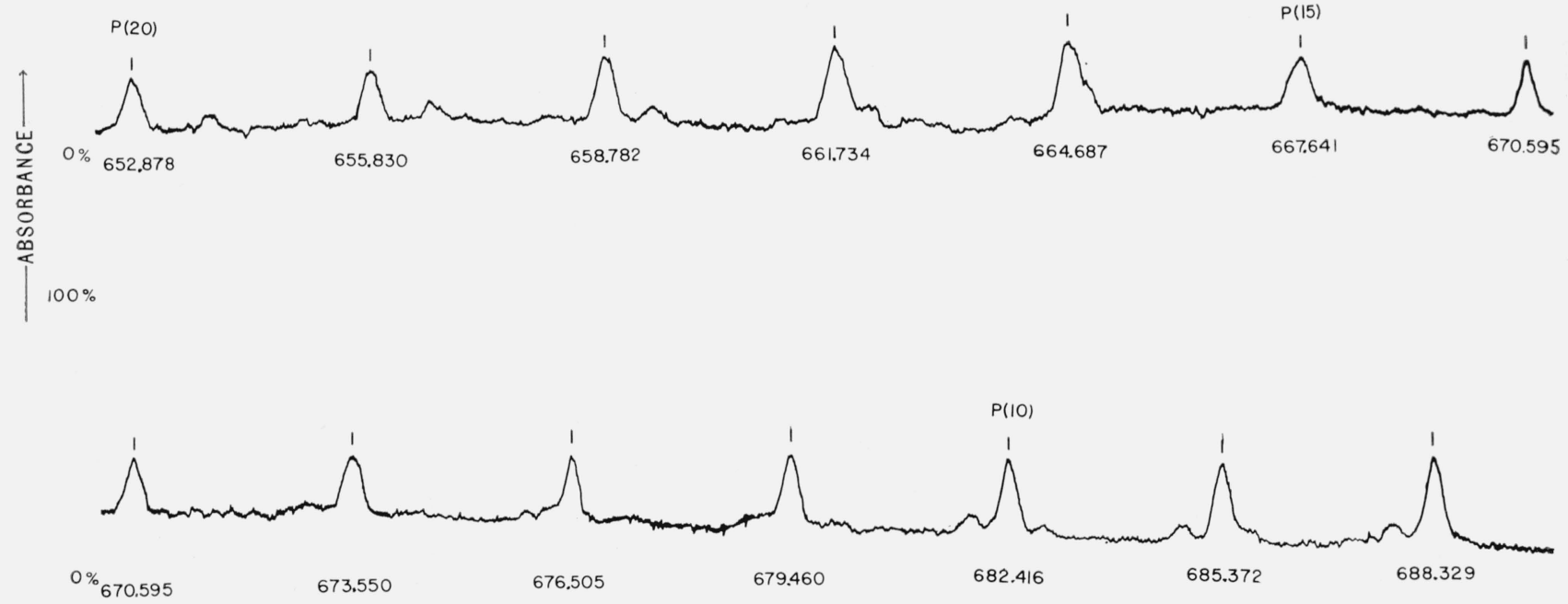

$100 \%$

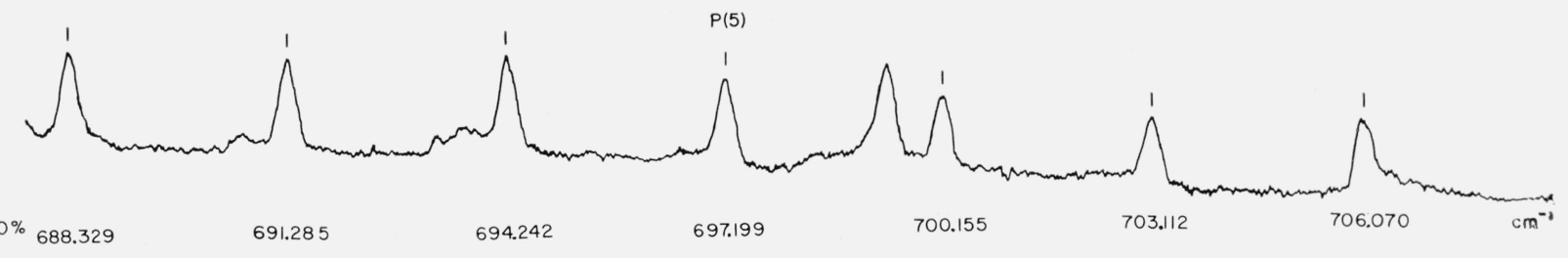

Figure 2. $\nu_{2}$ band of $\mathrm{HCN}$ at $14 \mu$.

353 
SOURCE CARBON ARC

PATH LENGTH $20 \mathrm{~cm}$

PRESSURE

$100 \% \quad P(2) \quad 1.5 \mathrm{~cm} \mathrm{Hg}$

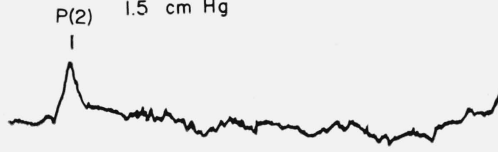

$0 \% \quad 706.070$

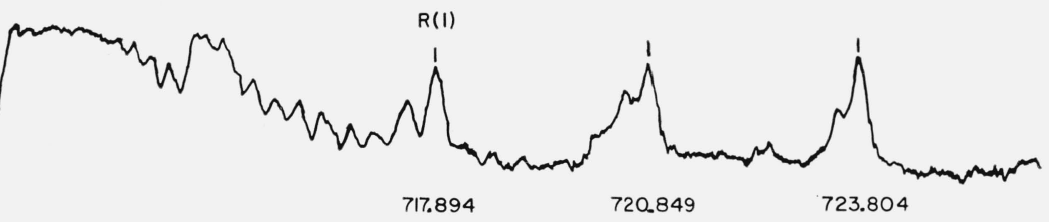

$R(5)$

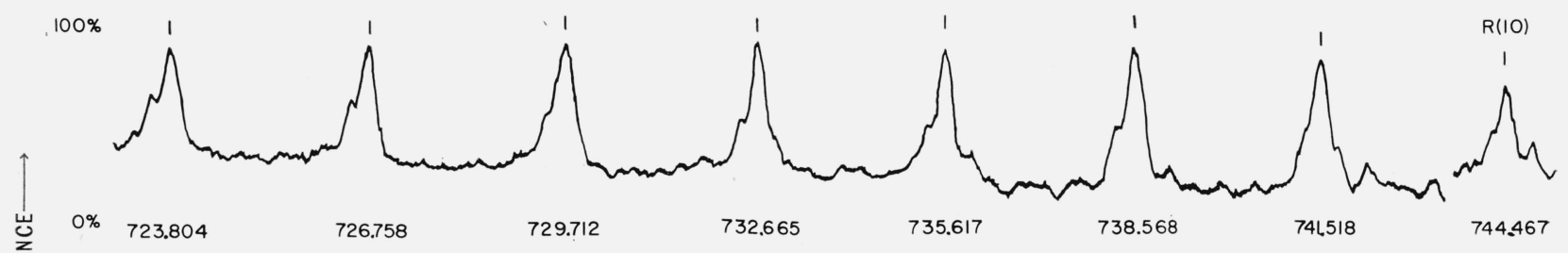

$100 \%$

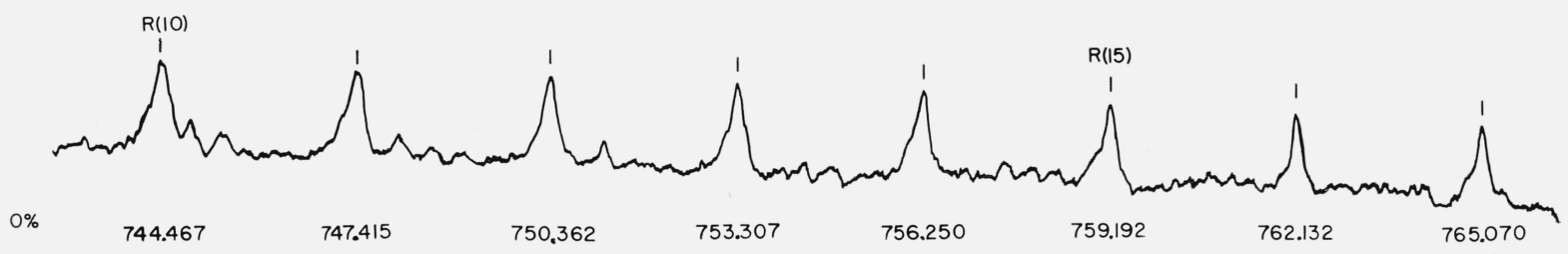

$100 \%$

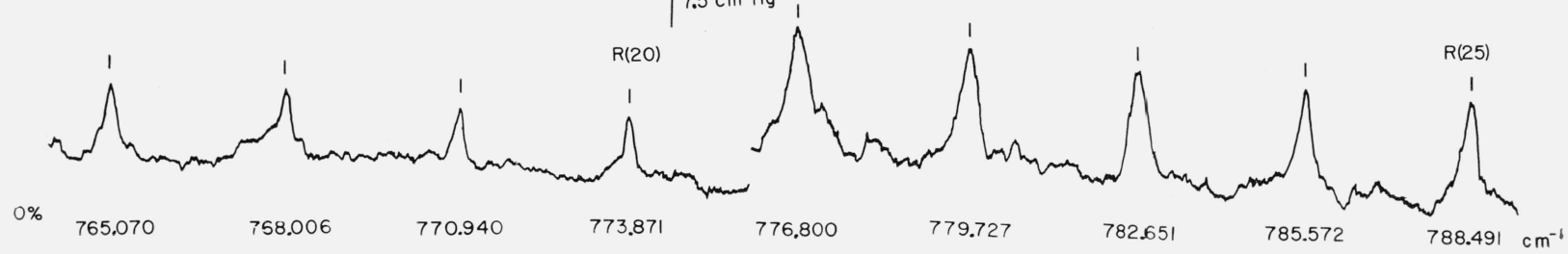

Figure 2. band of $\mathrm{HCN}$ at $14 \mu \nu_{2}$.-Continued. 


\section{Wave Numbers of the Pure Rotational Spectrum of $\mathrm{CO}, \mathrm{HCN}$, and $\mathrm{N}_{2} \mathrm{O}$}

Employing the rotational constants of the carbon monoxide [8, 9], hydrogen cyanide [10, 7], and the nitrous oxide $[10,11]$ molecules, the positions of their pure rotational spectra have been computed independently at The Ohio State University and the Bureau of Standards. The results are summarized in table 1 . The path lengths and pressures necessary for the observation of these far infrared spectra are furnished as footnotes to the table.

TABLE 1. Calculated positions of the pure rotational lines* of the $\mathrm{C}^{12} \mathrm{O}^{16}, \mathrm{~N}_{2}{ }^{14} \mathrm{O}^{16}$, and $\mathrm{HC}^{12} \mathrm{~N}^{14}$ molecules (vacuum $\mathrm{cm}^{-1}$ )

\begin{tabular}{|c|c|c|c|}
\hline$J$ & $\mathrm{C}^{12} \mathrm{O}^{16}$ & $\mathrm{~N}_{2}{ }^{14} \mathrm{O}^{16}$ & $\mathrm{HC}^{12} \mathrm{~N}^{14}$ \\
\hline $\begin{array}{l}0 \\
1 \\
2 \\
3 \\
4\end{array}$ & $\begin{array}{r}3.84_{5} \\
7.69_{0} \\
11.53_{4} \\
15.37_{9} \\
19.22_{2}\end{array}$ & $\begin{array}{l}0.83_{8} \\
1.67_{6} \\
2.51_{4} \\
3.35_{2} \\
4.19_{0}\end{array}$ & $\begin{array}{r}2.95{ }_{6} \\
5.91_{3} \\
8.86_{9} \\
11.82_{5} \\
14.78_{1}\end{array}$ \\
\hline $\begin{array}{l}5 \\
6 \\
7 \\
8 \\
9\end{array}$ & $\begin{array}{l}23.06_{5} \\
26.90_{7} \\
30.748 \\
34.58_{8} \\
38.42_{6}\end{array}$ & $\begin{array}{l}\text { 5. } 02_{8} \\
5.86_{6} \\
6.70_{4} \\
7.54_{2} \\
8.38_{0}\end{array}$ & $\begin{array}{l}\text { 17. } 73_{6} \\
20.69_{1} \\
23.64_{6} \\
26.59_{9} \\
29.55_{3}\end{array}$ \\
\hline $\begin{array}{l}10 \\
11 \\
12 \\
13 \\
14\end{array}$ & $\begin{array}{l}42.26_{3} \\
46.09_{8} \\
49.93_{2} \\
53.76_{3} \\
57.59_{3}\end{array}$ & $\begin{array}{r}9.21_{7} \\
10.05_{5} \\
10.89_{3} \\
11.73_{0} \\
12.56_{8}\end{array}$ & $\begin{array}{l}32.50_{5} \\
35.457 \\
38.40_{8} \\
41.358 \\
44.30_{7}\end{array}$ \\
\hline $\begin{array}{l}15 \\
16 \\
17 \\
18 \\
19\end{array}$ & $\begin{array}{l}61.42_{0} \\
65.24_{5} \\
69.068 \\
72.88_{8} \\
76.70_{5}\end{array}$ & $\begin{array}{l}13.40_{5} \\
14.24_{3} \\
15.08_{0} \\
15.91_{8} \\
16.75_{5}\end{array}$ & $\begin{array}{l}47.25_{5} \\
50.20_{2} \\
53.14_{8} \\
56.09_{2} \\
59.03_{6}\end{array}$ \\
\hline $\begin{array}{l}20 \\
21 \\
22 \\
23 \\
24\end{array}$ & $\begin{array}{l}80.51_{9} \\
84.33_{0} \\
88.13_{8} \\
91.94_{3} \\
95.74_{4}\end{array}$ & $\begin{array}{l}17.59_{2} \\
18.42_{9} \\
19.26_{6} \\
20.10_{3} \\
20.94_{0}\end{array}$ & $\begin{array}{l}61.97_{7} \\
64.91_{8} \\
67.85_{6} \\
70.79_{3} \\
73.72_{9}\end{array}$ \\
\hline $\begin{array}{l}25 \\
26 \\
27 \\
28 \\
29\end{array}$ & $\begin{array}{r}99.54_{1} \\
103.33_{4} \\
107.12_{4} \\
110.90_{9} \\
114.69_{0}\end{array}$ & $\begin{array}{l}21.77_{6} \\
22.61_{3} \\
23.44_{9} \\
24.28_{5} \\
25.12_{2}\end{array}$ & $\begin{array}{l}76.66_{3} \\
79.59_{5} \\
82.52_{4} \\
85.45_{3} \\
88.37_{9}\end{array}$ \\
\hline $\begin{array}{l}30 \\
31 \\
32 \\
33 \\
34\end{array}$ & $118.46_{7}$ & $\begin{array}{l}25.958 \\
26.79_{4} \\
27.62_{9} \\
28.46_{5} \\
29.30_{1}\end{array}$ & $\begin{array}{r}91.30 \\
94.22 \\
97.14 \\
100.06 \\
102.98\end{array}$ \\
\hline $\begin{array}{l}35 \\
36 \\
37 \\
38 \\
39\end{array}$ & & $\begin{array}{l}30.13_{6} \\
30.97_{1} \\
31.80_{6} \\
32.64_{1} \\
33.47_{6}\end{array}$ & $\begin{array}{l}105.89 \\
108.80 \\
111.71 \\
114.61 \\
117.51\end{array}$ \\
\hline $\begin{array}{l}40 \\
41 \\
42 \\
43 \\
44\end{array}$ & & $\begin{array}{l}34.31_{0} \\
35.14_{5} \\
35.97_{9} \\
36.81_{3} \\
37.647\end{array}$ & 120.41 \\
\hline $\begin{array}{l}45 \\
46 \\
47 \\
48 \\
49\end{array}$ & & $\begin{array}{l}38.48_{1} \\
39.31_{4} \\
40.14_{7} \\
40.98_{0} \\
41.81_{3}\end{array}$ & \\
\hline 50 & & $42.64_{6}$ & \\
\hline
\end{tabular}

*Path length $40 \mathrm{~cm}$ at pressures $2-3 \mathrm{~cm}$ of $\mathrm{Hg}$ for $\mathrm{HCN}$ and $40-60 \mathrm{~cm}$ of $\mathrm{Hg}$ for $\mathrm{CO}$ and $\mathrm{N}_{2} \mathrm{O}$.

\section{Wave Numbers of the $\mathrm{H}_{2} \mathrm{O}$ Lines in the Far Infrared}

The pure rotational spectrum of water vapor extends from 10 to $5000 \mu$, and many of the lines are intense from 25 to $400 \mu$. By selecting lines which are not seriously overlapped, a number of calibrating points can be obtained. It was considered desirable to provide a map of the pure rotational lines of the $\mathrm{H}_{2} \mathrm{O}$ molecule with the wave numbers marked on the spectrum. Figure 3 shows such a map of the water vapor lines as obtained with a Perkin-Elmer model 301 far infrared spectrophotometer under the conditions stated in the legend for the figure. The spectral position of each of the lines is indicated on the figure. These values have been derived by Benedict [12] after analyzing all the available data pertaining to the vibration rotation and pure rotational spectra of the $\mathrm{H}_{2} \mathrm{O}$ molecule. The internal consistency of these data have been examined on the spectra shown in figure 3 . Table 2 summarizes the findings. Tracings of the spectrum of atmospheric

TABLE 2. Verification of the internal consistency pertaining to the data of the water vapor lines

\begin{tabular}{|c|c|c|c|}
\hline Lines used & $\begin{array}{l}\text { Interpolated* } \\
\text { less value in } \\
\text { column } 1\end{array}$ & Lines used & $\begin{array}{l}\text { Interpolated* } \\
\text { less value in } \\
\text { column } 3\end{array}$ \\
\hline $\begin{array}{c}c m^{-1} \\
301.87 \\
298.42 \\
290.74 \\
289.46 \\
285.98\end{array}$ & $\begin{array}{l}c m^{-1} \\
+0.08 \\
+0.09 \\
-0.13 \\
+0.01\end{array}$ & $\begin{array}{c}\mathrm{cm}^{-1} \\
136.71 \\
161.79 \\
160.17 \\
-.--\end{array}$ & $\begin{array}{c}\mathrm{cm}^{-1} \\
-\cdots-.- \\
-0.03 \\
-0.03 \\
--. .-\end{array}$ \\
\hline $\begin{array}{l}248.87 \\
247.94 \\
245.34 \\
---- \\
227.83 \\
226.27 \\
223.72 \\
221.67 \\
214.59 \\
213.95 \\
212.59 \\
208.46\end{array}$ & $\begin{array}{l}-0.16 \\
+0.13 \\
\\
+0.10 \\
-0.06 \\
+0.06 \\
+0.06 \\
-0.03 \\
-0.01 \\
+0.02\end{array}$ & $\begin{array}{l}152.50 \\
151.30 \\
159.52 \\
149.06 \\
144.96 \\
141.46 \\
140.70 \\
1399.02 \\
135.89 \\
135.06 \\
133.43\end{array}$ & $\begin{array}{l}-0.24 \\
+0.08 \\
+0.15 \\
+0.13 \\
+0.03 \\
-0.01 \\
- \\
-0.06 \\
+0.08 \\
-0.14 \\
-\end{array}$ \\
\hline $\begin{array}{l}194.37 \\
193.45 \\
188.21 \\
183.46 \\
181.40 \\
116.64 \\
111.11 \\
107.79 \\
107.15 \\
106.12 \\
105.67\end{array}$ & $\begin{array}{r}- \\
+0.03 \\
-0.16 \\
+0.08 \\
-0.04 \\
-0.07 \\
+0.01 \\
0.00 \\
-0.01 \\
-0.03 \\
+0.04\end{array}$ & $\begin{array}{l}127.02 \\
122.88 \\
121.88 \\
120.50 \\
120.12 \\
117.92 \\
-\end{array}$ & $\begin{array}{l}-0.06 \\
-0.07 \\
+0.08 \\
-0.10 \\
+0.07 \\
-\end{array}$ \\
\hline $\begin{array}{r}100.53 \\
99.07 \\
96.05 \\
92.54 \\
89.53 \\
88.87 \\
88.06 \\
85.60 \\
82.11 \\
80.98 \\
79.77 \\
78.97 \\
78.21\end{array}$ & $\begin{array}{l}-0.03 \\
+0.07 \\
-0.05 \\
+0.09 \\
-0.03 \\
-0.09 \\
+0.10 \\
-0.01 \\
+0.05 \\
0.00 \\
-0.08 \\
+0.08\end{array}$ & 55.69 & -0.04 \\
\hline $\begin{array}{l}74.09 \\
73.24 \\
72.21\end{array}$ & $\begin{array}{l}+0.04 \\
+0.05\end{array}$ & & \\
\hline -.....- & -..-- & & \\
\hline
\end{tabular}

*Interpolations are made between alternate lines, e.g., the value for line $298.42 \mathrm{~cm}^{-1}$ was obtained by linearly i nterpolating between lines 301.87 and $290.74 \mathrm{~cm}^{-1}$. 

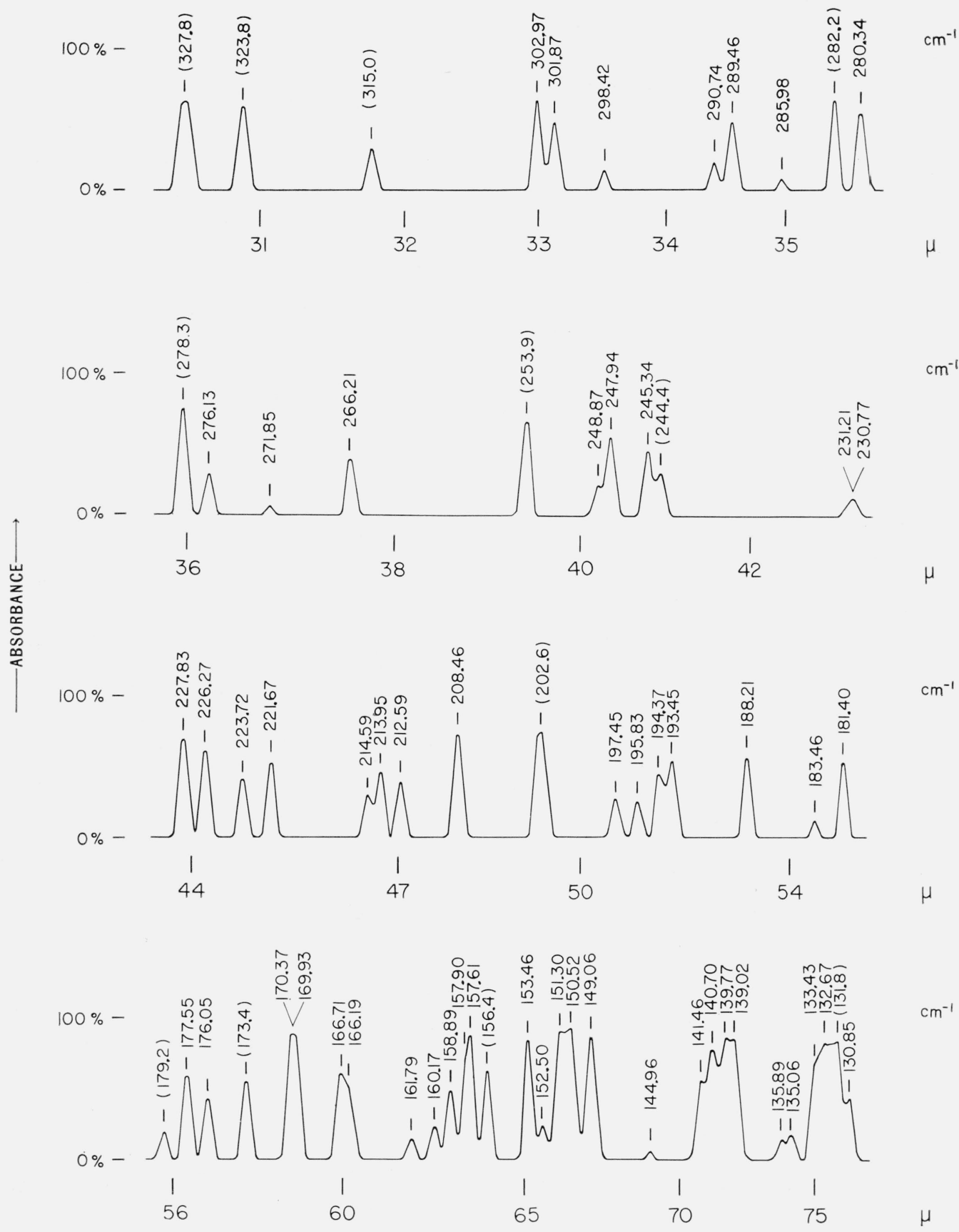

Figure 3. Pure rotational lines of $\mathrm{H}_{2} \mathrm{O}$ recorded with a Perkin-Elmer model 301 spectrophotometer.

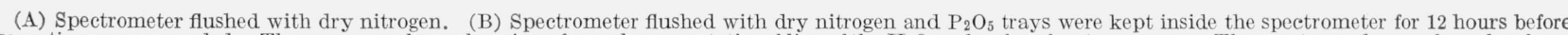

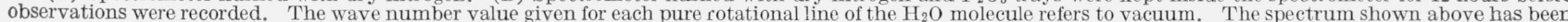

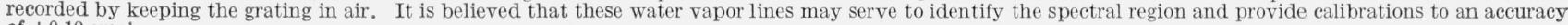
of $\pm 0.10 \mathrm{~cm}^{-1}$. 


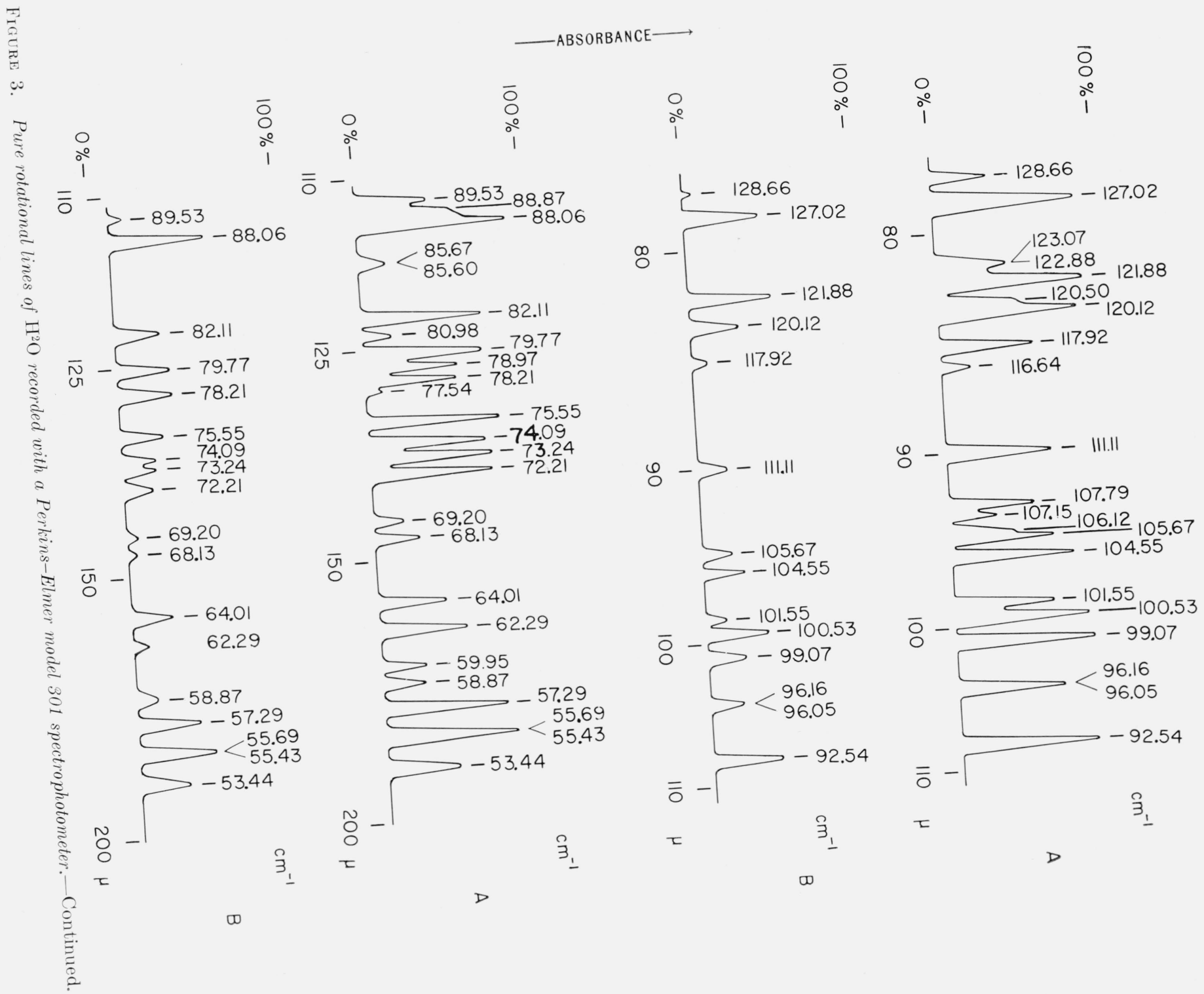


water vapor obtained with a small grating spectrometer in the region 600 to $166 \mathrm{~cm}^{-1}$ have been published by Plyler et al. [13]. Also, the paper by Rao et al. [14] gives a map and measurements (to an accuracy of $\pm 0.02 \mathrm{~cm}^{-1}$ ) of the pure rotational lines of the $\mathrm{H}_{2} \mathrm{O}$ molecule, in the region 550 to 270 $\mathrm{cm}^{-1}$ as obtained with a 1000 lines per inch Bausch and Lomb plane replica grating installed in a Pfundtype vacuum spectrometer.

One of us (KNR) wishes to express his deep gratitude to the U.S. Army Research Office (Durham, N.C.) and to the National Science Foundation for their financial support through contracts with the Ohio State University Research Foundation. Our thanks are also due to Dr. W. S. Benedict for supplying us with his analysis of the presently available data pertaining to the infrared rotational lines of the $\mathrm{H}_{2} \mathrm{O}$ molecule.

\section{References}

[1] Calibrating Wave Numbers for the Calibration of Infrared Spectrometers, published by the International Union of Pure and Applied Chemistry, Butterworths, London (1961).

[2] C. C. Helms and R. E. Anacreon, J. Opt. Soc. Am. 50, 511 (1960).

[3] Earle K. Plyler, L. R. Blaine, and E. D. Tidwell, J. Research NBS 55, 279 (1955).

[4] K. Narahari Rao, L. R. Ryan, and Harald H. Nielsen, J. Opt. Soc. Am. 49, 216 (1959).

[5] K. Narahari Rao, T. J. Coburn, J. S. Garing, K. Rossmann, and H. H. Nielsen, J. Opt. Soc. Am. 49, 221 (1959).

[6] D. H. Rank, J. Opt. Soc. Am. 50, 657 (1960).

[7] K. Narahari Rao, W. W. Brim, and J. M. Hoffman, J. Opt. Soc. Am. 50, 228 (1960).

[8] D. H. Rank, A. H. Geunther, G. D. Saksena, J. N. Shearer, and T. A. Wiggins, J. Opt. Soc. Am. 47, 686 (1957).

[9] Earle K. Plyler, L. R. Blaine, and W. S. Connor, J. Opt. Soc. Am. 45, 102 (1955).

[10] D. H. Rank, D. P. Eastman, B. S. Rao, and T. A. Wiggins, J. Opt. Soc. Am. 51, 929 (1961).

[11] E. D. Tidwell, E. K. Plyler, and W. S. Benedict, J. Opt. Soc. Am. 50, 1243 (1960).

[12] W. S. Benedict (private communication).

[13] L. R. Blaine, E. K. Plyler, and W. S. Benedict, J. Research NBS 66A (Phys. and Chem.) No. 3,223 (1962).

[14] K. Narahari Rao, W. W. Brim, V. L. Sinnett, and R. H. Wilson, J. Opt. Soc. Am. 52, 862 (1962). 